\title{
Low-cost virtual instrumentation of PV panel characteristics using Excel and Arduino in comparison with traditional instrumentation
}

\author{
Aboubakr El Hammoumi*, Saad Motahhir, Abdelilah Chalh, Abdelaziz El Ghzizal and Aziz Derouich
}

\begin{abstract}
This paper presents a low-cost solution of virtual instrumentation to provide a new technique for real-time instrumentation of the PV panel characteristics such as voltage, current and power. The system design is based on a low-cost Arduino acquisition board. The acquisition is made through a low-cost current and voltage sensors, and data are presented in Excel by using the PLX-DAQ data acquisition Excel Macro, which allows communication between the ATMega328 microcontroller of an Arduino UNO board and the computer by UART bus. Hence, the $I-V$ and $P-V$ characteristics, which processed under real-time conditions, can be obtained directly and plotted on an Excel spreadsheet without needing to reprogram the microcontroller. A comparison between this low-cost virtual instrumentation and the traditional instrumentation is drawn in this work. It is found that our solution presents several benefits compared to the traditional solution such as the data can be presented in graphical form in real time. Thus, several experimental tests to confirm the effectiveness of the developed virtual instrumentation system are presented in this study.
\end{abstract}

Keywords: Real-time, PV panel, Arduino, PLX-DAQ, Excel, Instrumentation

\section{Introduction}

PV panels are the main equipment of solar power generation system that serve to convert solar light energy into DC electrical energy (Ozdemir et al. 2014; Jean et al. 2015). The energy generated by the PV systems depends on the environmental conditions such as temperature, solar irradiance, direction and spectrum of sunlight (Singh 2013; Motahhir et al. 2015). And under the standard test conditions (STC), characteristics of the PV panel are provided by the manufacturers (Eltawil and Zhao 2010). However, the PV characteristics are unknown out of STC (Hohm and Ropp 2003). Therefore, the measurement of the PV characteristics is required (Mahrane et al. 2010), which is why different traditional instruments are used in this context such as multimeters. However, by using this kind of instruments it is difficult to make a correct reading by human during a rapid change of

\footnotetext{
*Correspondence: aboubakr.elhammoumi@usmba.ac.ma Laboratory of Production Engineering, Energy and Sustainable Development, Higher School of Technology, SMBA University, km 5, Rte Imouzzer, Fez, Morocco
}

temperature or solar radiation. Thus, a few samples can be captured, and as a result, the characteristics obtained and traced manually do not give enough information on the state of the PV system. Nevertheless, there are some oscilloscopes which can record data through USB communication, but these instruments are more expensive and they are not available for many researchers (Mahrane et al. 2010; Velleman Instruments 2017).

On the other hand, also virtual instruments can be used to measure the PV characteristics. Many virtual instruments have been proposed in the literature such as a Data Logger Solar Panel Parameters as in Santos and Setiaji (2013), Fuentes et al. (2014), Alonsogarcia et al. (2006) which collect output data only in text file formats and cannot be taken directly in real time. Therefore, many realtime virtual instrumentation systems for the PV panel have also been proposed in the literature, such as virtual instrumentation for real-time PV system monitoring based on LabVIEW (Koutroulis and Kalaitzakis 2003; Ulieru et al. 2010) and virtual instrumentation by the standard simulation software MATLAB (Chouder et al. 2012). In addition, different commercial software solutions are available 
and are mostly used for the real-time measurement of PV characteristics (Silvestre 2003). Generally, all the proposed virtual instruments in the literature are low cost compared to traditional instruments. The most proposed systems are often based on LabVIEW or MATLAB tools, but they are costly and complex. Therefore, this work proposes a very low cost real-time virtual instrument system which is based on Arduino Uno and Excel. Besides, Arduino is a low-cost board since Excel is installed in almost every computer. Moreover, this system is based on low-cost current and voltage sensors. The proposed system acquires the current, voltage and the output power generated by the PV panel in real time. The acquisition of measurement data from the current and voltage sensors is recorded directly into Excel using the PLX-DAQ data acquisition Excel Macro, which allows communication between the microcontroller (ATMega328) of the Arduino UNO board and Excel by using UART bus. The main advantages of the proposed technique manifested in its simplicity and its low demand for hardware components. In addition, this technique allows researchers to acquire and to visualize the characteristics of PV systems that they need in their work with a simpler, cheaper and faster way. Hence, this technique is more effective compared to the implementation of a virtual instrument system with LabVIEW or MATLAB tools, which require several technical skills and a preliminary training on these tools. On the other hand, to show the effectiveness of our system, this work presents a comparison between the $I-V$ and $P-V$ characteristics of the PV panel which are obtained by the proposed solution and those obtained by traditional instrumentation through a multimeters. It should be mentioned that a PSIM model of PV panel is used as a reference, and this model is already validated in Motahhir et al. (2017), Banu and Istrate (2012), Villalva et al. (2009).

The paper is organized as follows. The PV panel model is presented in "PV panel model" section. The design and description of the proposed PV panel real-time virtual instrumentation system are done in "Real-time virtual instrumentation system" section. The experiments and testings are presented in "Results and discussion" section. Finally, "Conclusions" section summarizes this paper.

\section{PV panel model}

A PV panel is composed of several PV cells placed in parallel or in series which convert the solar energy into DC electrical energy (Ozdemir et al. 2014). The equivalent circuit of the PV panel is presented in Fig. 1 (Motahhir et al. 2015, 2016).

As shown in Fig. 1, the PV panel is modeled by a current source in parallel with a diode, a shunt resistor and a series resistor. The output current generated by the PV panel can be given by Eq. (1) (Motahhir et al. 2015, 2016).

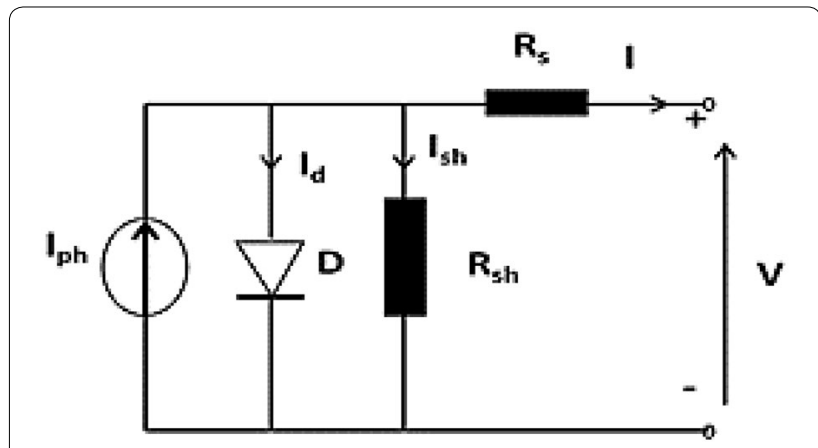

Fig. 1 PV cell equivalent circuit

Table 1 Characteristics of the PV Module TDC-M20-36 AT STC $\left(1000 \mathrm{~W} / \mathrm{m}^{2}, 25^{\circ} \mathrm{C}\right)$

\begin{tabular}{ll}
\hline Characteristics & TDC-M20-36 \\
\hline Maximum power, $P_{\max }$ & $20 \mathrm{~W}$ \\
Voltage at $P_{\text {max }}, V_{\mathrm{mp}}$ & $18.76 \mathrm{~V}$ \\
Current at $P_{\text {max }} I_{\mathrm{mp}}$ & $1.07 \mathrm{~A}$ \\
Short-circuit current, $I_{\mathrm{sc}}$ & $1.17 \mathrm{~A}$ \\
Open-circuit voltage, $V_{\text {oc }}$ & $22.70 \mathrm{~V}$ \\
Temperature coefficient of $V_{\text {oc' }}, K_{\mathrm{v}}$ & $-0.35 \% /{ }^{\circ} \mathrm{C}$ \\
Temperature coefficient of $I_{\mathrm{sc}} K_{\mathrm{i}}$ & $0.043 \% /{ }^{\circ} \mathrm{C}$ \\
Number of cells & 36 \\
Light-generated current, $I_{\text {ph }}$ & $1.173 \mathrm{~A}$ \\
Diode saturation current, $I_{0}$ & $2.6797 \mathrm{e}-11 \mathrm{~A}$ \\
Ideality factor & 1.0036 \\
Shunt resistance $R_{\text {sh }}$ & $405.962 \Omega$ \\
Series resistance $R_{\mathrm{s}}$ & $1.0547 \Omega$ \\
\hline
\end{tabular}

$$
I=I_{\mathrm{ph}}-I_{\mathrm{s}}\left(\exp \frac{q\left(V+R_{\mathrm{s}} I\right)}{a K T N_{\mathrm{s}}}-1\right)-\frac{\left(V+I R_{\mathrm{s}}\right)}{R_{\mathrm{sh}}}
$$

In this study, the TDC-M20-36 solar panel is used and Table 1 presents its characteristics (TDC-M20-36 solar panel 2018).

In order to validate the effectiveness as well as the accuracy of the proposed real-time virtual instrumentation, the $I-V$ and $P-V$ characteristics of the PV panel which are obtained by the proposed solution and those obtained through the multimeters will be compared with the $I-V$ and $P-V$ characteristics which are, in turn, obtained by the PV panel model under PSIM. This model is already validated in Motahhir et al. (2017), Banu and Istrate (2012), Villalva et al. (2009), and the results have shown that the $I-V$ and $P-V$ characteristics given by the PV Panel PSIM model are in accordance with those obtained by the experimental test. This model is presented in Fig. 2, and the $I-V$ and $P-V_{\mathrm{g}}$ curves of this model under STC are shown in Fig. 3. 


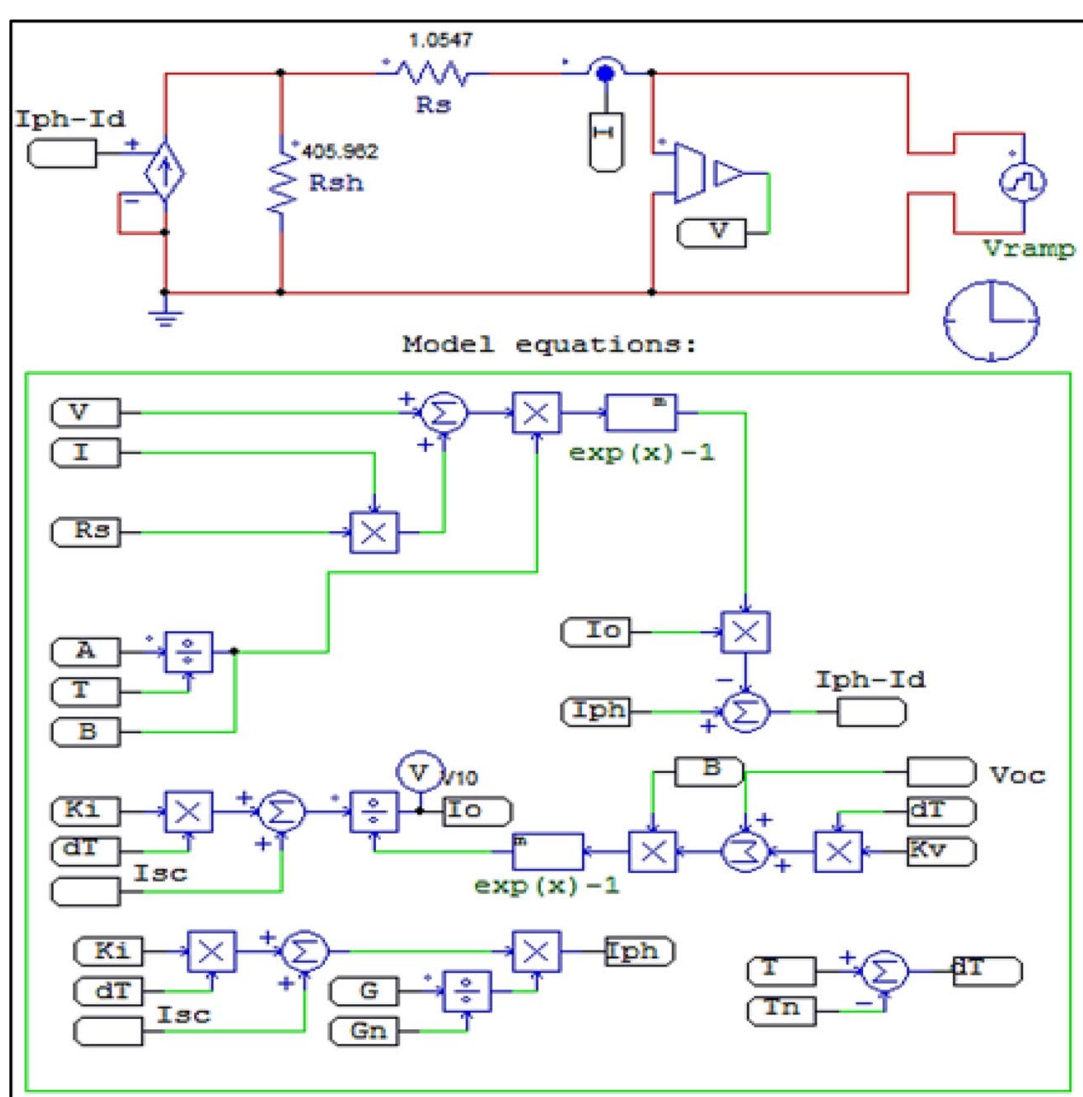

Spec of TDC-M20-36 pv solar panel 20w:

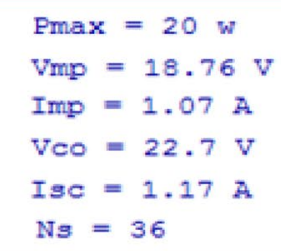

Parameters of one single module:
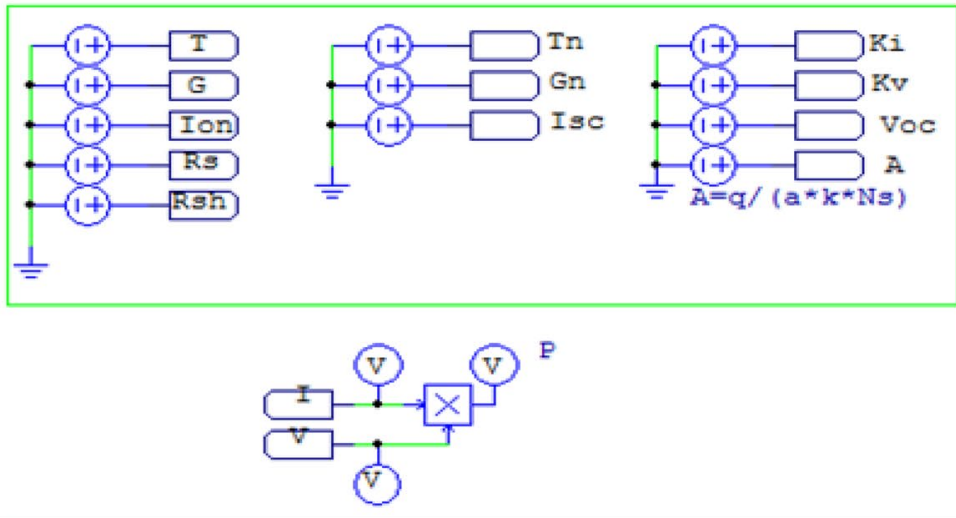

Fig. 2 The PSIM model of PV panel 


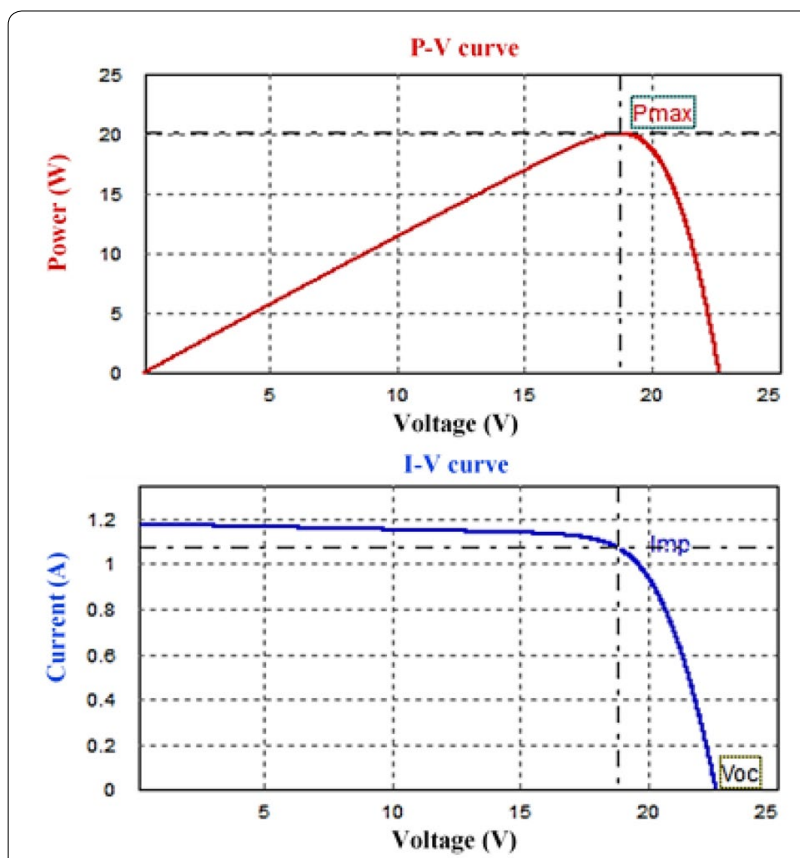

Fig. $3 I-V$ and $P-V$ characteristics for PV panel under PSIM at STC ( $T=25^{\circ} \mathrm{C}$ and $\mathrm{G}=1000 \mathrm{~W} / \mathrm{m}^{2}$ )

\section{Real-time virtual instrumentation system}

The proposed technique of real-time virtual instrumentation is made using PLX-DAQ data acquisition Excel Macro, where data can be acquired directly in real time into Microsoft Excel (PLX-DAQ 2017). The PLX-DAQ Excel Macro can acquire up to 26 channels of data from microcontroller (PLX-DAQ 2017). The structure of the equipment used in the virtual instrumentation system is shown in Fig. 4.
The PV current and voltage are obtained through the current and voltage sensors. The output of the two sensors is then transmitted to the microcontroller of the Arduino UNO board. The PLX-DAQ Excel Macro allows communication between the microcontroller and Excel spreadsheet using UART bus. During the acquisition process, the data obtained are stored and plotted in real time in the Excel spreadsheet. As any embedded system, the proposed real-time virtual instrumentation system is divided into two parts: hardware and software.

\section{Hardware}

In order to acquire the PV panel characteristics, different components are required such as a data acquisition board, current sensor and voltage sensor.

\section{Arduino UNO: a data acquisition board}

The embedded board used in this work is Arduino UNO, in which the ATMega328 microcontroller is integrated. It is a low-cost board (Motahhir et al. 2017). The Arduino UNO board depicted in Fig. 5 can be powered by a DC power supply or through USB connection with computer. This board provides 14 digital input/output pins and 6 analog inputs, and it can be programmed by the Arduino IDE software (Arduino-Software 2018).

\section{Voltage sensor}

The PV voltage is measured by a voltage sensor module. This module can reduce the input voltage up to 5 times of the original voltage and it is used to reduce the PV output voltage $(V)$ which is between 0 and $22.7 \mathrm{~V}$ to another voltage $\left(V_{\mathrm{d}}\right)$ between 0 and $5 \mathrm{~V}$ to be measurable by Arduino, because the Arduino analog input is limited to a 5 V. Figure 6 shows the selected voltage sensor,

\section{Serial}

\section{communication}
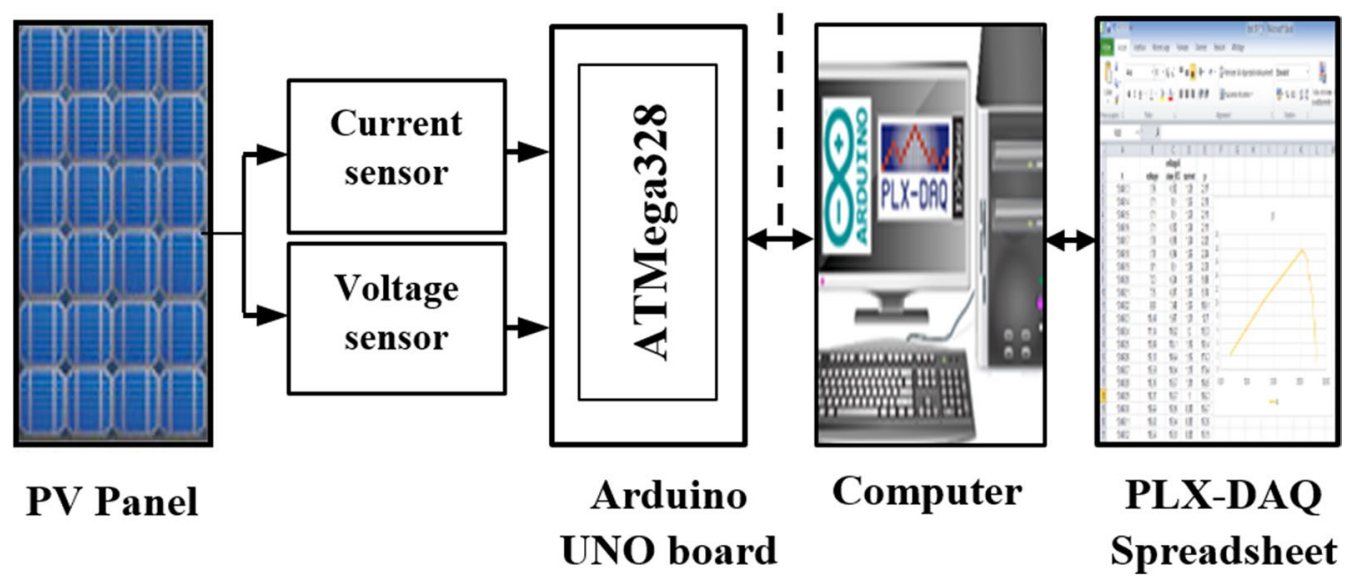

Fig. 4 Schematic of PV panel output characteristics instrumentation system 


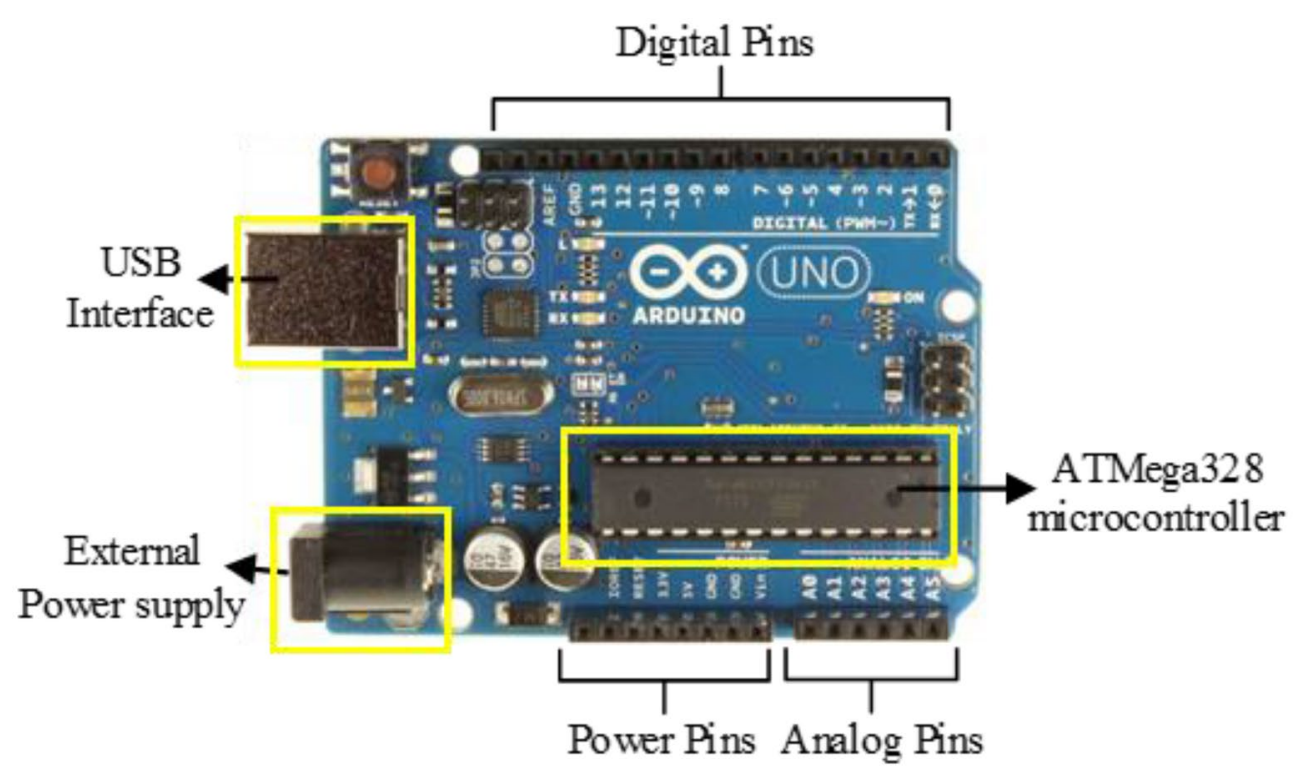

Fig. 5 Arduino UNO board

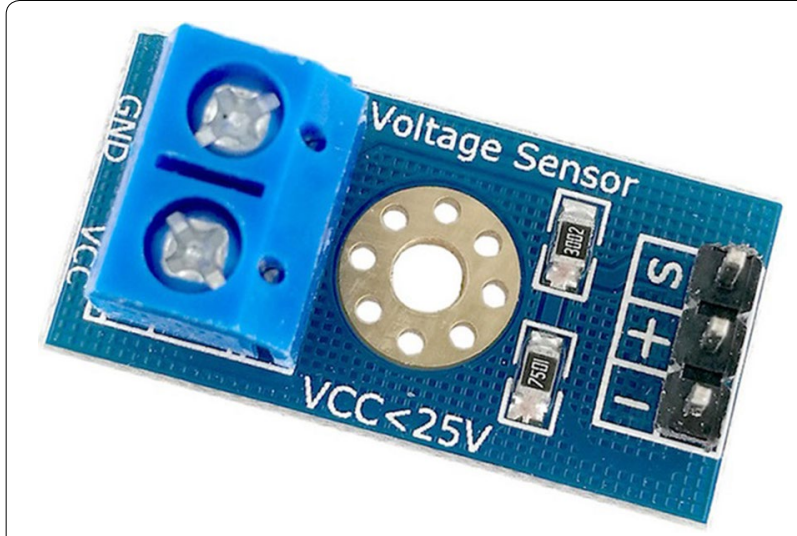

Fig. 6 F031-06 voltage sensor module

Table 2 Specifications of the F031-06 voltage sensor module

\begin{tabular}{ll}
\hline Specifications & FO31-06 voltage sensor module \\
\hline Input voltage range & DC $0-25 \mathrm{~V}$ \\
Voltage detection range & DC $0.02445-25 \mathrm{~V}$ \\
Analog voltage resolution & $0.00489 \mathrm{~V}$ \\
\hline
\end{tabular}

Table 2 presents its specifications, and Table 3 presents its connectors with Arduino board (Voltage Sensor Module 2018). According to the manufacturer, this is basically a voltage divider using two series resistors as shown in Fig. 7 (Voltage Sensor Module 2018).
Table 3 Connectors of the F031-06 voltage sensor module

\begin{tabular}{ll}
\hline Pin symbol & Descriptions \\
\hline VCC & $\begin{array}{c}\text { is connected to the high side of the voltage to be meas- } \\
\text { ured }\end{array}$ \\
GND & $\begin{array}{l}\text { is connected to the low side of the voltage to be measured, } \\
\text { this is the same electrical point as Arduino ground }\end{array}$ \\
$\mathrm{S}$ & is connected to an Arduino analog input, this is the meas- \\
& ured output \\
+ & is not connected \\
- & is connected to Arduino ground \\
\hline
\end{tabular}

The voltage sensor is put in parallel with the load as shown in Fig. 10; then, the output of this sensor is transmitted to the analog-digital converter (ADC) of the Arduino microcontroller. The ADC provides a digital value $\left(V_{\text {out } 1}\right)$ which varies between 0 and 1023 , because the latter is encoded in 10 bits. Therefore, the analog voltage resolution of the voltage sensor module is $0.00489 \mathrm{~V}$ ( $5 \mathrm{~V} / 1023)$, and the minimum input voltage detected by this module is $0.02445 \mathrm{~V}(0.00489 \mathrm{~V} \times 5)$. Since the voltage range of the sensor module is $[0,25 \mathrm{~V}]$, the divider's voltage ratio as shown in Eq. (2) is equal to 0.2. Therefore, the real output voltage of PV panel can be obtained by the equation presented in (3).

$$
V_{\mathrm{d}}=\frac{R_{2}}{\left(R_{1}+R_{2}\right)} \times V
$$



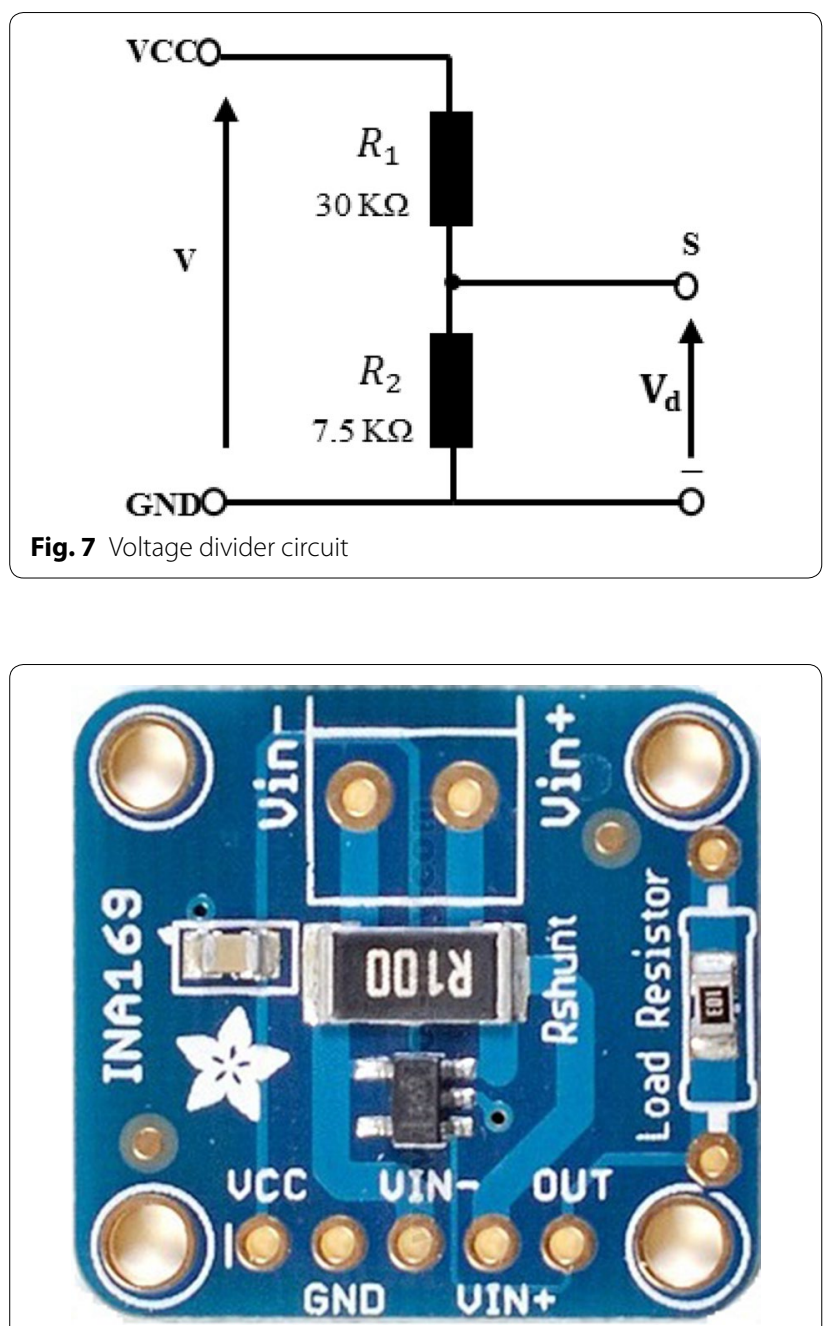

Fig. 8 INA169 current sensor module

$$
V=\frac{\left(R_{1}+R_{2}\right)}{R_{1}} \times V_{\text {out } 1} \times \frac{5}{1023}
$$

\section{Current sensor}

A current sensor (INA169) is used in order to measure the image of the PV panel's current (INA169 Datasheet 2017). Figure 8 shows the selected current sensor, Table 4 presents its specifications, and Table 5 presents its connectors with Arduino board.

The INA169 current sensor circuit is shown in Fig. 9. The INA169 is a "high-side, unipolar, current shunt
Table 4 Specifications of the INA169 current sensor module

\begin{tabular}{ll}
\hline Specifications & INA169 current sensor module \\
\hline Common mode voltage range & DC $2.7-60 \mathrm{~V}$ \\
Full-scale sense input voltage & $500 \mathrm{mV}$ \\
Input offset voltage (max) & $1000 \mu \mathrm{VN} \pm$ \\
Input offset drift (max) & $\pm 1 \mu \mathrm{V} /{ }^{\circ} \mathrm{C}$ \\
Nonlinearity error (max) & $\pm 0.1 \%$ \\
Total output error (max) & $\pm 2 \%$ \\
Common mode rejection ratio (Typ) & $120 \mathrm{~dB}$ \\
Bandwidth & $440 \mathrm{kHz}$ \\
Supply voltage range & $\mathrm{DC} 2.7-60 \mathrm{~V}$ \\
Operating temperature range & $-40 \mathrm{to} 85^{\circ} \mathrm{C}$ \\
Quiescent current & $60 \mu \mathrm{A}$ \\
\hline
\end{tabular}

Table 5 Connectors of the INA169 current sensor module

\begin{tabular}{ll}
\hline Pin symbol & Descriptions \\
\hline VCC & $\begin{array}{l}\text { is connected to the Arduino VCC }(+5 \mathrm{~V}) \text {, this is the power } \\
\text { supply to the INA169 } \\
\text { is connected to the Arduino ground, this is the same elec- } \\
\text { trical point as the low side of the source (PV panel) }\end{array}$ \\
VIN+ & $\begin{array}{l}\text { is connected to the positive side of the source. } \\
\text { is connected to the positive side of the load }\end{array}$ \\
VOUT & $\begin{array}{l}\text { is connected to an Arduino analog input, this is the meas- } \\
\text { ured output }\end{array}$ \\
\hline
\end{tabular}

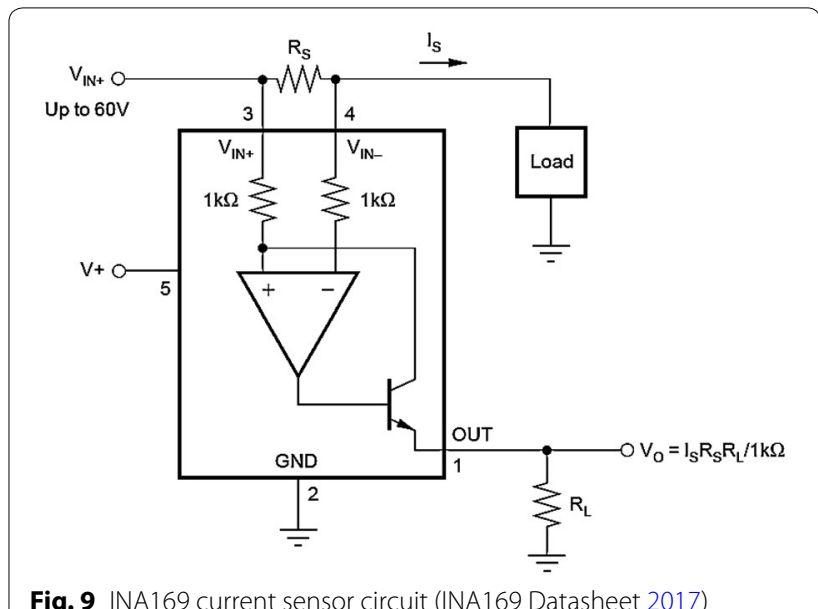

Fig. 9 INA169 current sensor circuit (INA169 Datasheet 2017) 


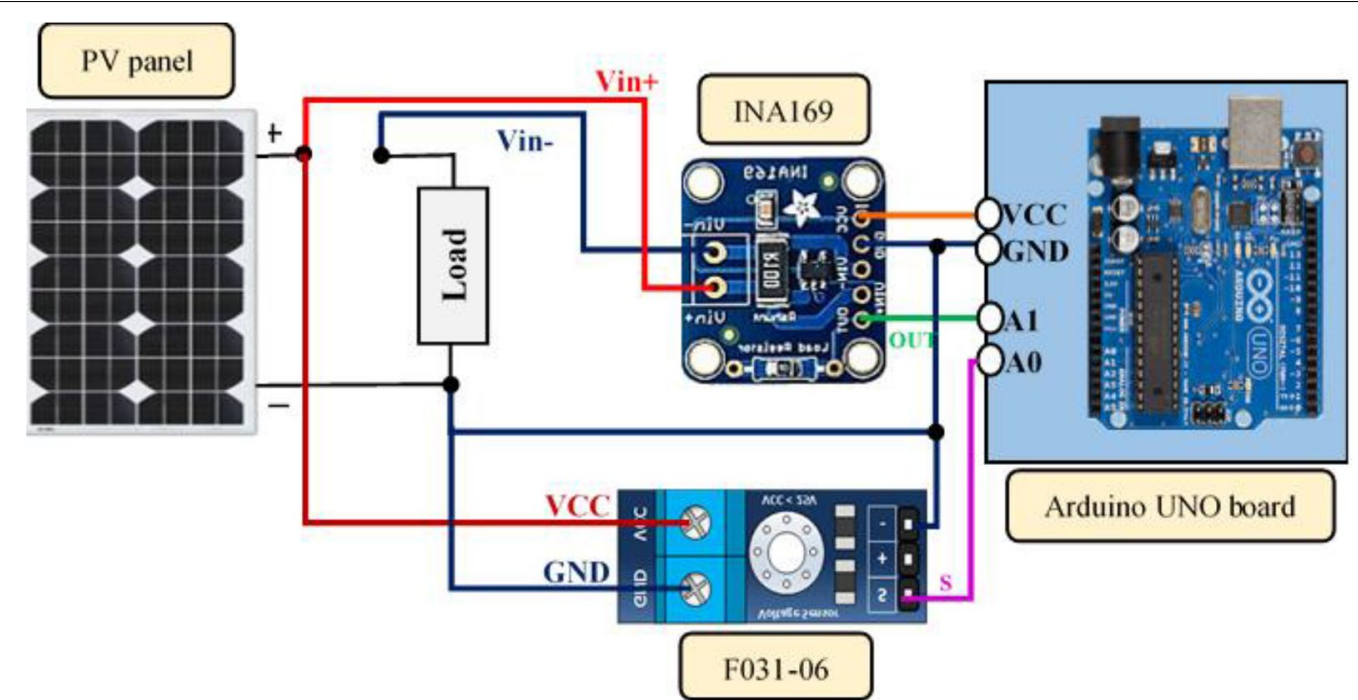

Fig. 10 Schematic view of the hardware components connected to the Arduino UNO

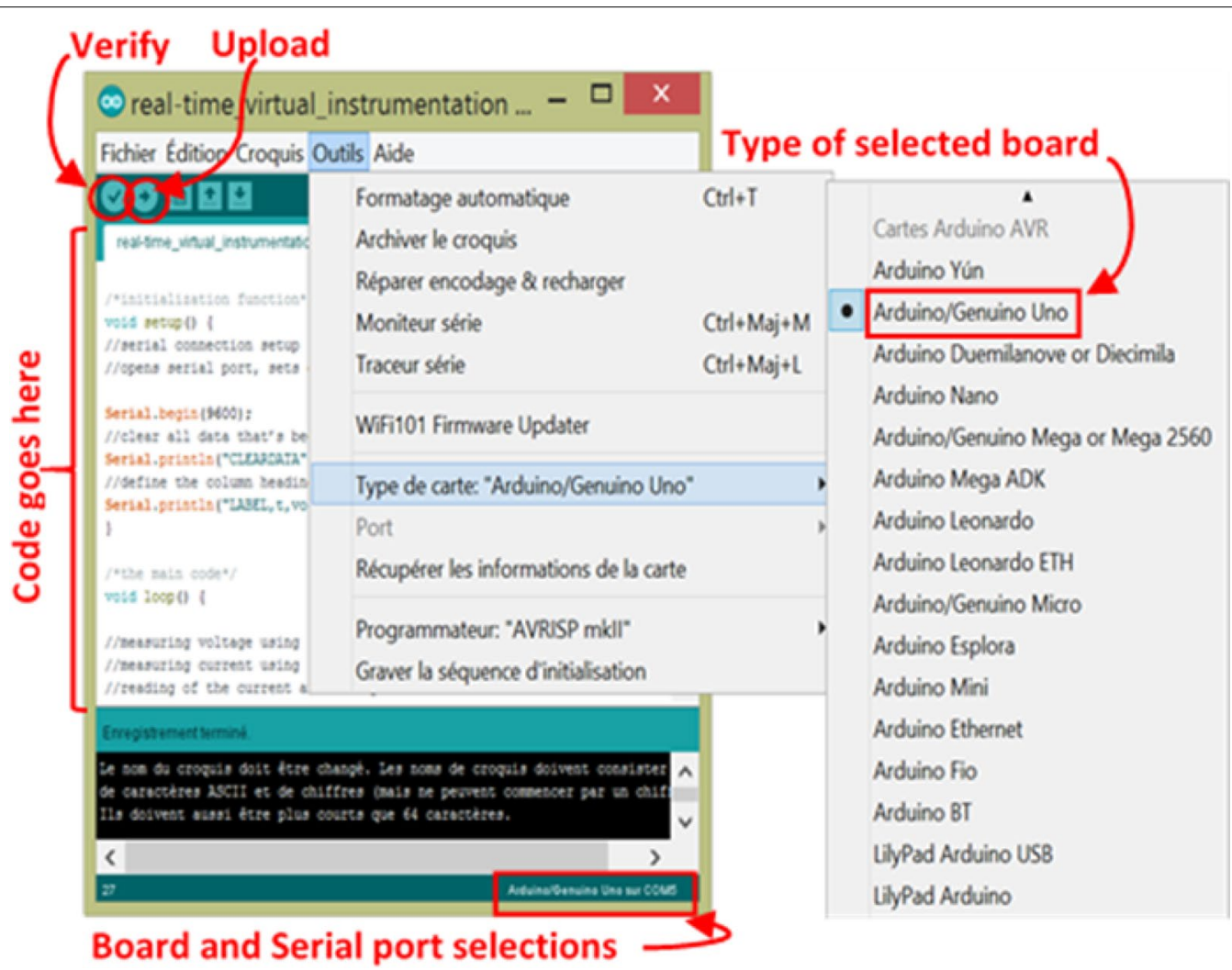

Fig. 11 IDE Software window 
monitor," meaning that it measures the voltage drop across a shunt resistor $\left(R_{\mathrm{s}}\right)$ which is placed on the positive power side (INA169 Datasheet 2017). The operational amplifier inside the INA169 module outputs a voltage based on the difference between the measured voltages $V_{\mathrm{IN}+}$ and $V_{\mathrm{IN}-}$. Then, the output voltage of the amplifier is converted to a current by the internal transistor, and this current is converted back to a voltage $\left(V_{\mathrm{o}}\right)$ when it passes through the load resistor $\left(R_{\mathrm{L}}\right)$ to the ground. Note that the $V_{\mathrm{o}}$ range depends on the voltage supplied by VCC (5 V in our case). Therefore, and according to Fig. 9, the measured current is obtained by the following equation (INA169 Datasheet 2017):

$$
I_{\mathrm{S}}=\frac{V_{\mathrm{o}} \times 1000}{R_{\mathrm{S}} \times R_{\mathrm{L}}}
$$

where $V_{\mathrm{o}}$ is the voltage at the output of the INA169; $R_{\mathrm{S}}$ is the value of the shunt resistor, and it defaults to $0.1 \Omega$; and $R_{\mathrm{L}}$ is the value of the output resistor, and it defaults to $10 \mathrm{~K} \Omega$.

However, the amplifier measures the voltage across the $0.1 \Omega, 1 \% / 2 \mathrm{~W}$, shunt resistor $\left(R_{\mathrm{S}}\right)$. Since the amplifier maximum input difference is $500 \mathrm{mV}$, this means that the INA169 can measure up to $5 \mathrm{~A}$ continuous. The output is a current that is drawn through the integrated $10 \mathrm{~K}$ resistor $\left(R_{\mathrm{L}}\right)$ so that the output voltage is $1 \mathrm{~V}$ per current. The output voltage $V_{\mathrm{o}}$ of the INA169 is the input voltage of an analog pin Arduino; then, this input is transmitted to the ADC of the microcontroller which provides a digital value $\left(V_{\text {out } 2}\right)$ that varies between 0 and 1023 . As a result, the image of the PV panel's output current can be obtained by the equation presented in (5). Since the ADC of the microcontroller is encoded in 10 bits, the reading resolution of sensing current is $0.00489 \mathrm{~A}$. The current

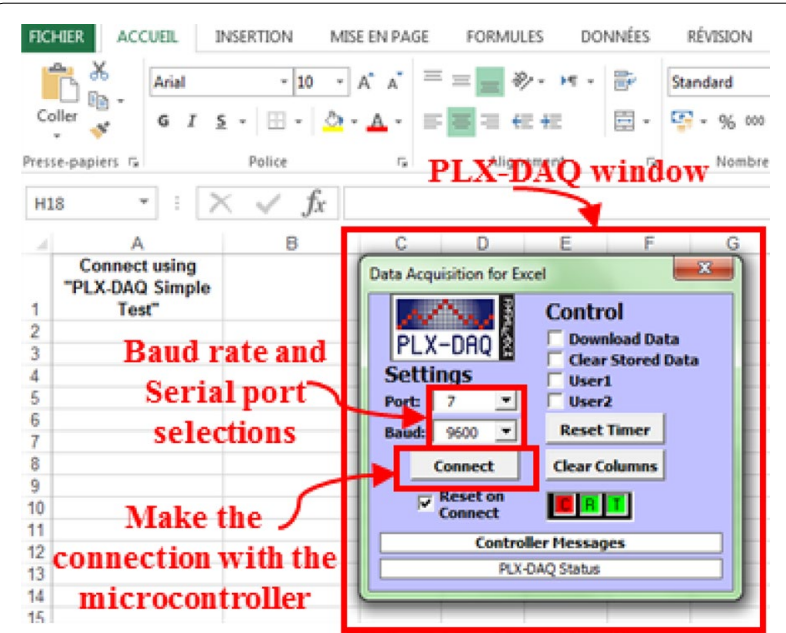

Fig. 12 PLX-DAQ Spreadsheet window sensor module is put in series between the positive side of the PV panel and that of the load as shown in Fig. 10.

$$
I=\frac{V_{\text {out } 2 \times 5}}{1023}
$$

\section{Software}

In the software part, we present the Arduino code and all software requested (PLX-DAQ Excel Macro and Arduino IDE) for the real-time virtual instrumentation system design and the guide to achieve this. Note that Arduino IDE and PLX-DAQ Excel Macro are both open source.

\section{Arduino IDE}

The Arduino IDE software makes it possible to write, modify a program and convert it into a series of instructions that are understandable for the microcontroller of an Arduino board. The IDE can run on Windows, Linux or Mac (Arduino-Software 2018). The used Arduino board in this work is programmed by the IDE that serves as a code editor and compiler and can transfer the program code to the microcontroller through USB cable. In order to achieve that, you will need to follow the next steps:

- Get the Arduino board and a USB cable.

- Download the Arduino IDE software from here (Arduino-Software 2018) (version: ARDUINO 1.8.5 for Windows) and install it.

- Launch the Arduino IDE application.

- Write the code of the program in the code box as shown in Fig. 11.

- Select the type of used board (Arduino UNO).

- Connect the board.

- Select the used serial port.

- Verify and upload the program to the Arduino microcontroller.

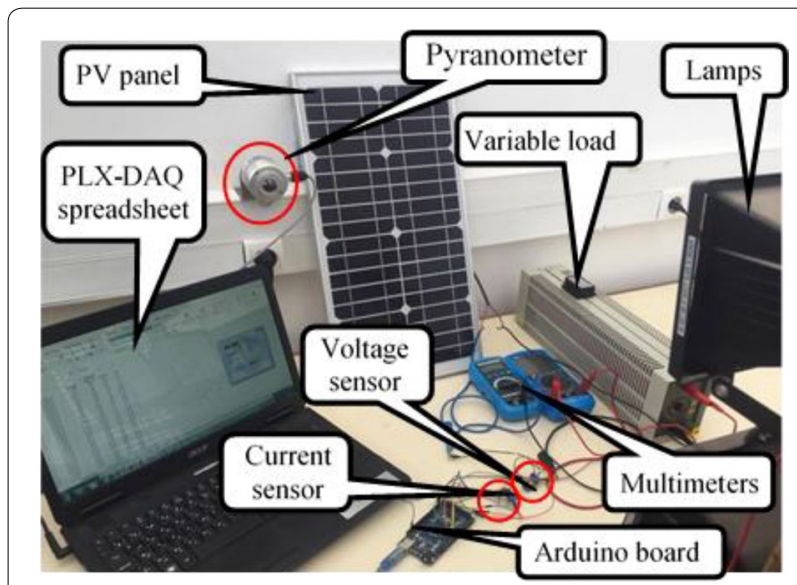

Fig. 13 Experimental setup of the virtual instrumentation system 


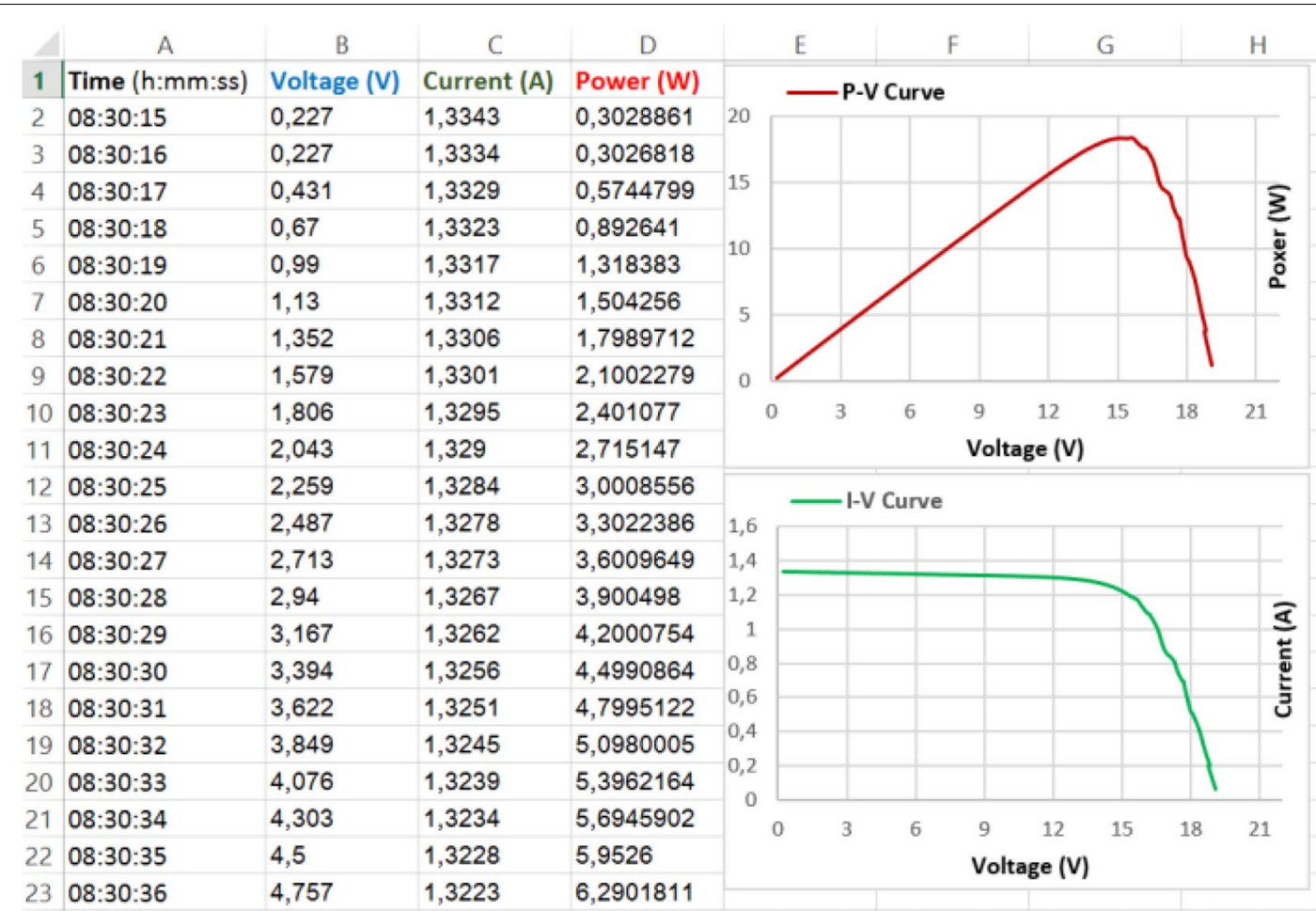

Fig. 14 A sample of experimentally measured data with real-time virtual instrumentation system

Table 6 Accuracy specifications of MU58A digital multimeter

\begin{tabular}{llll}
\hline Measurement & \multicolumn{3}{l}{$\begin{array}{l}\text { MU58A digital multimeter } \\
\text { Accuracy specifications }\end{array}$} \\
\cline { 2 - 4 } & Range & Resolution & Accuracy \\
\hline DC voltage (input imped- & $20 \mathrm{~V}$ & $10 \mathrm{mV}$ & $\pm(0.5 \%+1)$ \\
ance $\geq 10 \mathrm{M} \Omega$ ) & $200 \mathrm{~V}$ & $100 \mathrm{mV}$ & \\
DC current & $200 \mathrm{~mA}$ & $0.1 \mathrm{~mA}$ & $\pm(1.5 \%+1)$ \\
& $20 \mathrm{~A}$ & $10 \mathrm{~mA}$ & $\pm(2 \%+5)$
\end{tabular}

Accuracy: \pm ( $a \%$ reading $+b$ digits)

Operating temperature: $18-28^{\circ} \mathrm{C}$
Table 7 Accuracy specifications of ADM01 digital multimeter

\begin{tabular}{|c|c|c|}
\hline \multirow[t]{2}{*}{ Measurement } & \multicolumn{2}{|c|}{$\begin{array}{l}\text { ADM01 digital multim- } \\
\text { eter } \\
\text { Accuracy specifications }\end{array}$} \\
\hline & Range & Accuracy \\
\hline \multirow[t]{2}{*}{ DC voltage (input impedance: $10 \mathrm{M} \Omega$ ) } & $20 \mathrm{~V}$ & $\pm(0.5 \%+2)$ \\
\hline & $200 \mathrm{~V}$ & \\
\hline \multirow[t]{2}{*}{ DC current } & $200 \mathrm{~mA}$ & $\pm(1 \%+3)$ \\
\hline & $10 \mathrm{~A}$ & $\pm(3 \%+3)$ \\
\hline
\end{tabular}

Accuracy: \pm ( $a \%$ reading $+b$ digits) 


\section{PLX-DAQ}

The PLX-DAQ Excel Macro has been used for data acquisition from the Arduino microcontroller to an Excel Spreadsheet. We only need to download it from here (PLX-DAQ 2017). After installation, a folder named "PLX-DAQ" will automatically be created on the PC in which a shortcut named "PLX-DAQ Spreadsheet" is inside. Then as shown in Fig. 12, to establish the communication between the board and Excel, we just need to open the Spreadsheet and define the connections settings (baud rate and port) in PLX-DAQ window.

\section{Arduino program code}

The Arduino UNO board offers a simple way to communicate with a computer or other microcontrollers. The ATMega328 microcontroller of the Arduino UNO board provides a UART TTL $(5 \mathrm{~V})$ serial communication (Hemza et al. 2015). Then, an integrated circuit ATmega8U2 on the board connects this serial communication from the Arduino UNO's serial port to the computer's USB port, which appears as a virtual COM port in the PLX-DAQ window. The program code embedded in the Arduino UNO board, which allows to acquire the measured data of PV panel from sensors and send it to a PLX-DAQ Spreadsheet, is presented as follows:

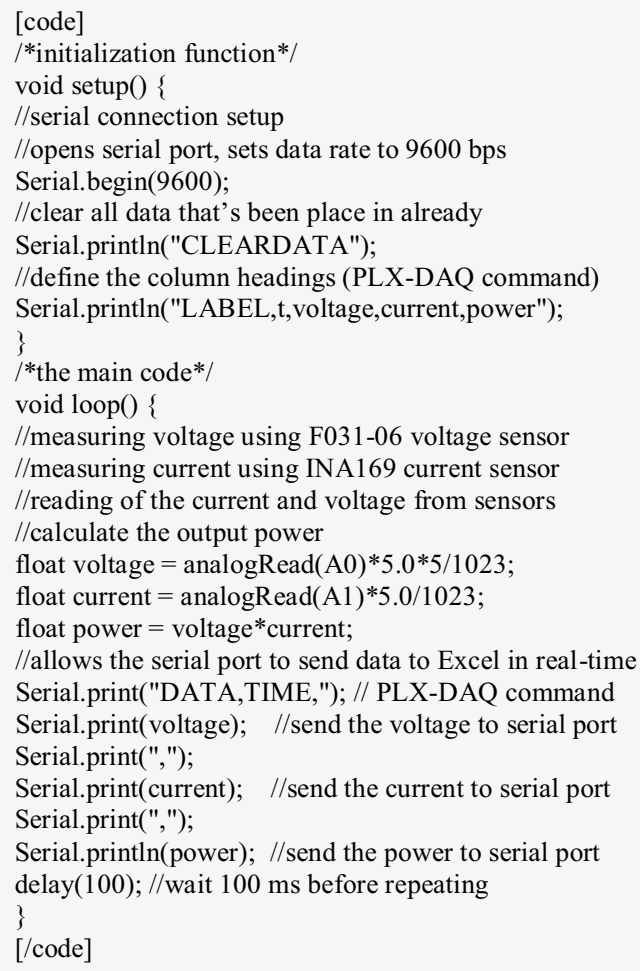

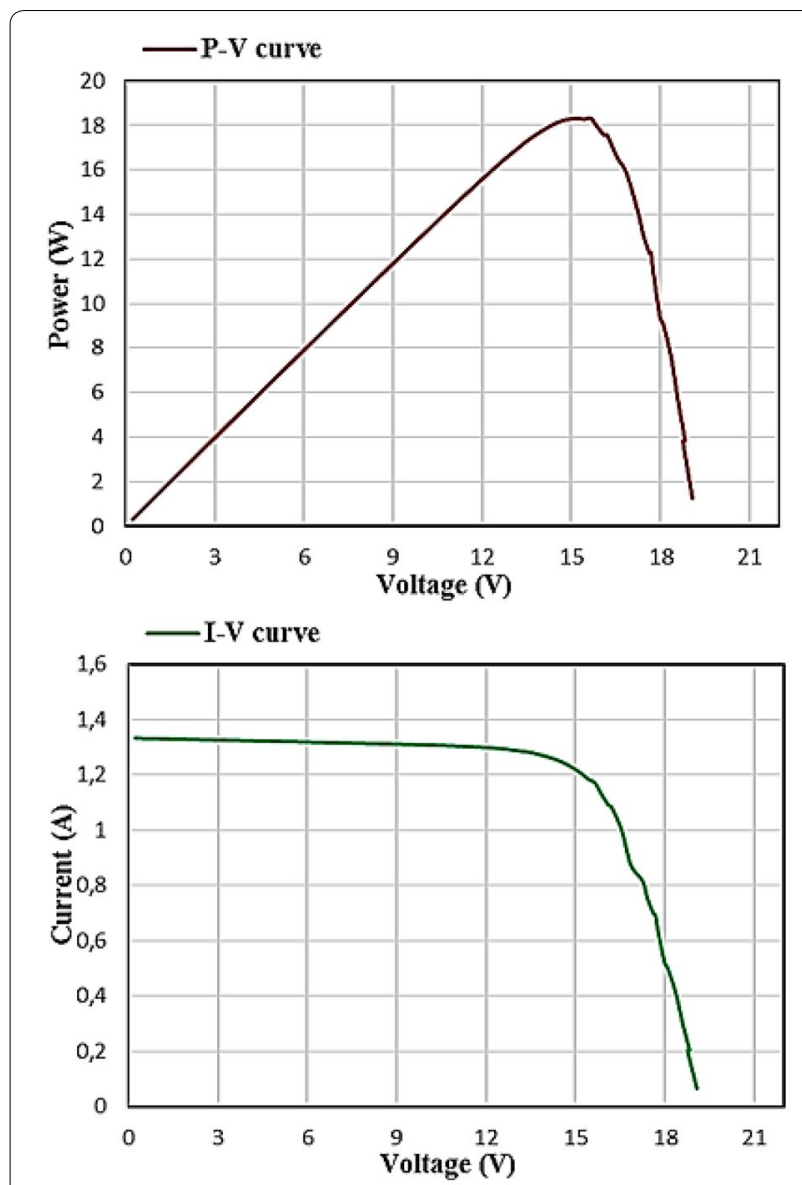

Fig. $15 I-V$ and $P-V$ characteristics for $P V$ panel by using virtual instrumentation (at $T=72^{\circ} \mathrm{C}$ and $\mathrm{G}=1100 \mathrm{~W} / \mathrm{m}^{2}$ )

\section{Results and discussion}

Figure 13 shows the experimental setup of the virtual instrumentation system. The microcontroller of Arduino board gets the PV panel output voltage and current which are measured by sensors and then computes the output power. Once the Arduino board is connected to the computer through a USB cable, we launch the PLXDAQ Excel Macro and define the serial port, where Arduino board is connected to the computer, and the baud rate $(9600 \mathrm{bit} / \mathrm{s})$ in the PLX-DAQ window after the latter is displayed as shown in Fig. 12. Note that the baud rate defined in PLX-DAQ window must be the same as that used in the program code embedded in Arduino board. Therefore, after clicking on "connect" the output data will be collected and displayed in real time on the Excel Spreadsheet as shown in Fig. 14.

As shown in Fig. 13, the data measured by the sensors are transmitted to the Excel in real time, and then, the 


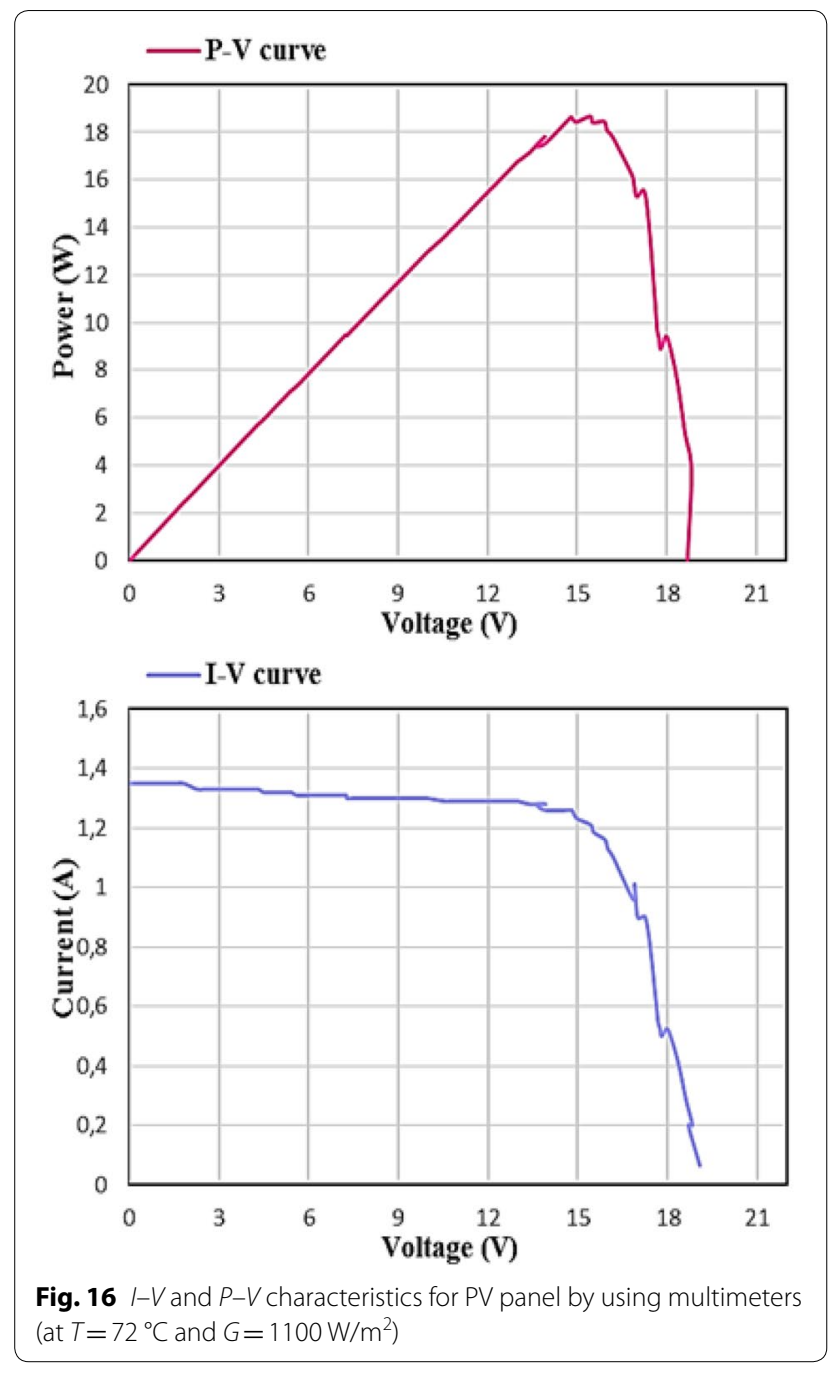

characteristics of the PV panel can be presented graphically. Two artificial lamps of 100 watts acting as a solar simulator are used. The light intensity is driven by varying manually a variable resistance between 0 and $330 \Omega$. A pyranometer is also used to measure the light radiation. The microcontroller is programmed to measure successively in each second the PV current, voltage and power. Concerning the traditional instrumentation, two multimeters are used for current and voltage measurement. Tables 6 and 7 present their accuracy specifications. The results of direct monitoring of the PV panel are shown in Fig. 14. $I-V$ and $P-V$ characteristics of the PV panel obtained by our virtual instrumentation system and those obtained by multimeters are presented in Figs. 15 and 16.

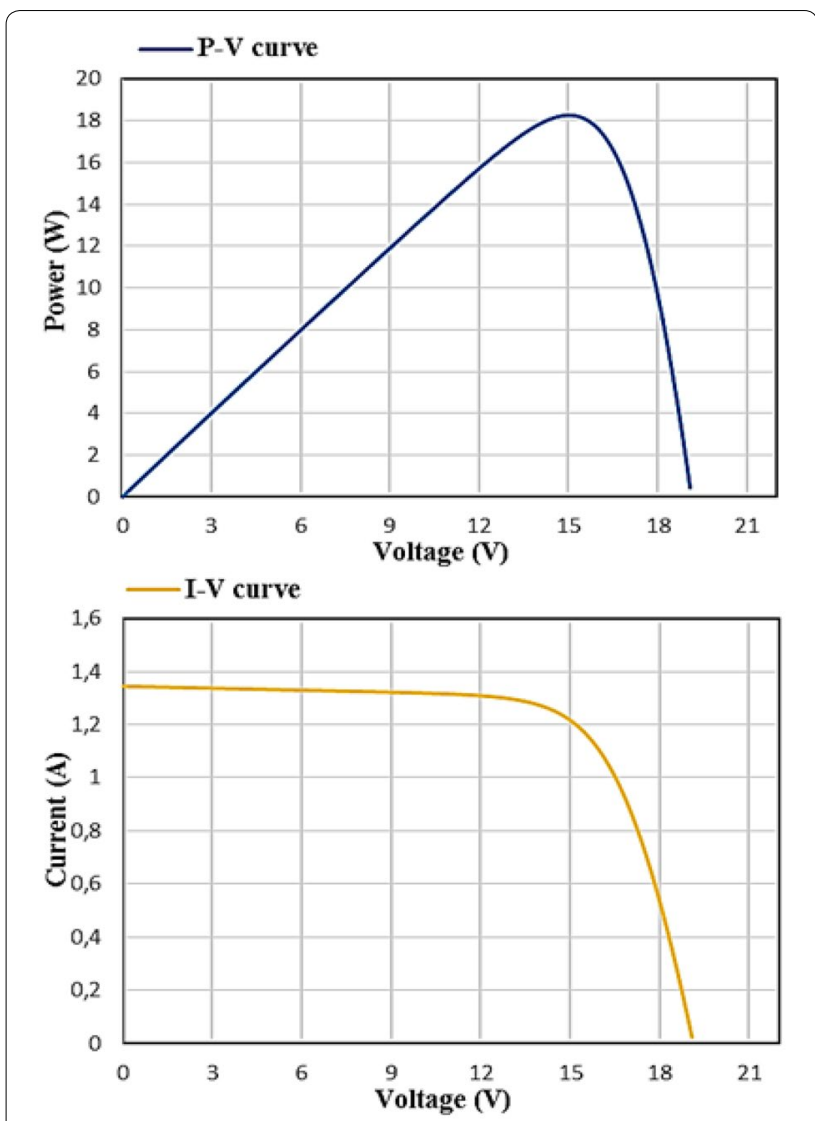

Fig. $17 L-V$ and $P-V$ characteristics for PV panel under PSIM

As was described previously in PV panel model section, the PV panel model under PSIM is used as a reference for validating the effectiveness and the accuracy of the proposed virtual instrument. Therefore, the PV characteristics which are obtained by the proposed solution and those obtained through the multimeters will be compared with the PV characteristics obtained by the PV panel model under PSIM. Figure 17 shows the $I-V$ and $P-V$ characteristics acquired by PSIM model (at $T=72{ }^{\circ} \mathrm{C}$ and $G=1100 \mathrm{~W} / \mathrm{m}^{2}$ ). In Fig. 18 , comparisons of PV panel PSIM model data with those of the experiment test by our virtual instrumentation and multimeters (at $T=72{ }^{\circ} \mathrm{C}$ and $G=1100 \mathrm{~W} / \mathrm{m}^{2}$ ) are presented. As shown in Fig. 18, the $P-V$ and $I-V$ characteristics for PV panel acquired by our virtual instrumentation are in accordance with the simulated data in both the current and the power curves with a good level of accuracy. Nevertheless, the curves obtained based on multimeters present small errors of accuracy due to peaks shown in both 

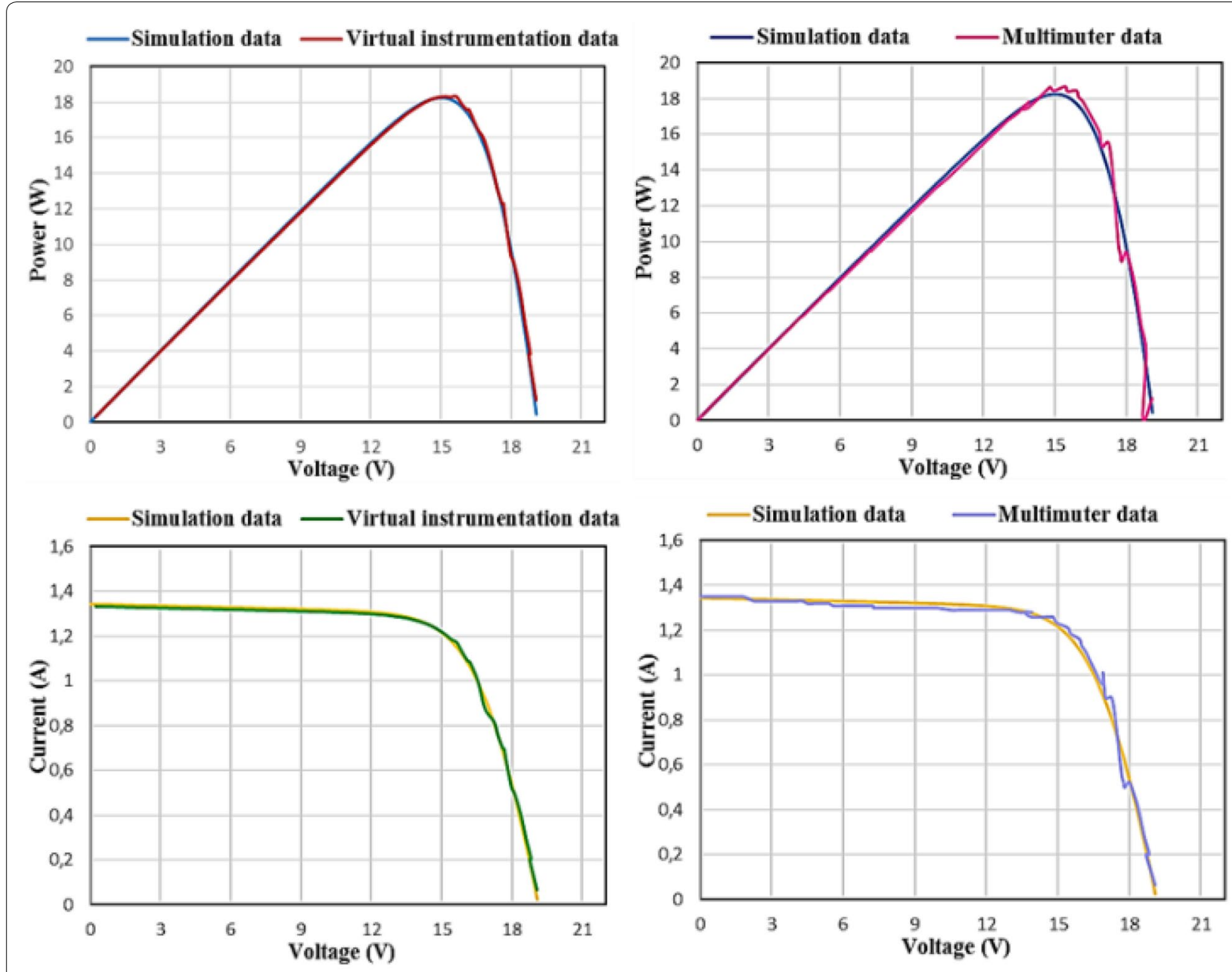

Fig. $18 I-V$ and $P-V$ model curves and experimental data of $P V$ panel

curves. This can be explained by the low accuracy of the multimeters used on the one hand, and the inability of the human to read all data on multimeters screen in real time at each moment during fast measurement variation on the other hand. Additionally, the error can be more significant for smaller measured samples than for larger ones. However, a real-time virtual instrumentation allows us to read each variation of measurements since they have recorded automatically thanks to real-time acquisition system.

The results of a test similar to the previous one for the virtual instrumentation are shown in Fig. 19, while the difference relates to decreasing the sample time from $1 \mathrm{~s}$ to only $100 \mathrm{~ms}$. As shown in Fig. 19, oscillations have appeared on the $I-V$ and $P-V$ curves. As a result, obtaining good $\mathrm{PV}$ characteristics requires a compromise between using small or large sample time. In our case, and as shown in Fig. 15, a sample time of $1 \mathrm{~s}$ is very useful for acquiring the characteristics of the used PV panel without oscillations.

In Fig. 20, the results of a monitoring test for current, voltage and power of the PV panel are presented. From the experimental results presented in Fig. 20, it can be seen that the PV panel produced a maximum power of $17.07 \mathrm{~W}$ at " $15 \mathrm{~h} 14 \mathrm{~min} 02 \mathrm{~s}$ " when a voltage of $14.15 \mathrm{~V}$ and a current of $1.20 \mathrm{~A}$ appear. Subsequently, the output power tends to a minimum value $822.2 \mathrm{~mW}$ when there is a voltage of $18.23 \mathrm{~V}$ and a current of $45.1 \mathrm{~mA}$. Hence, 

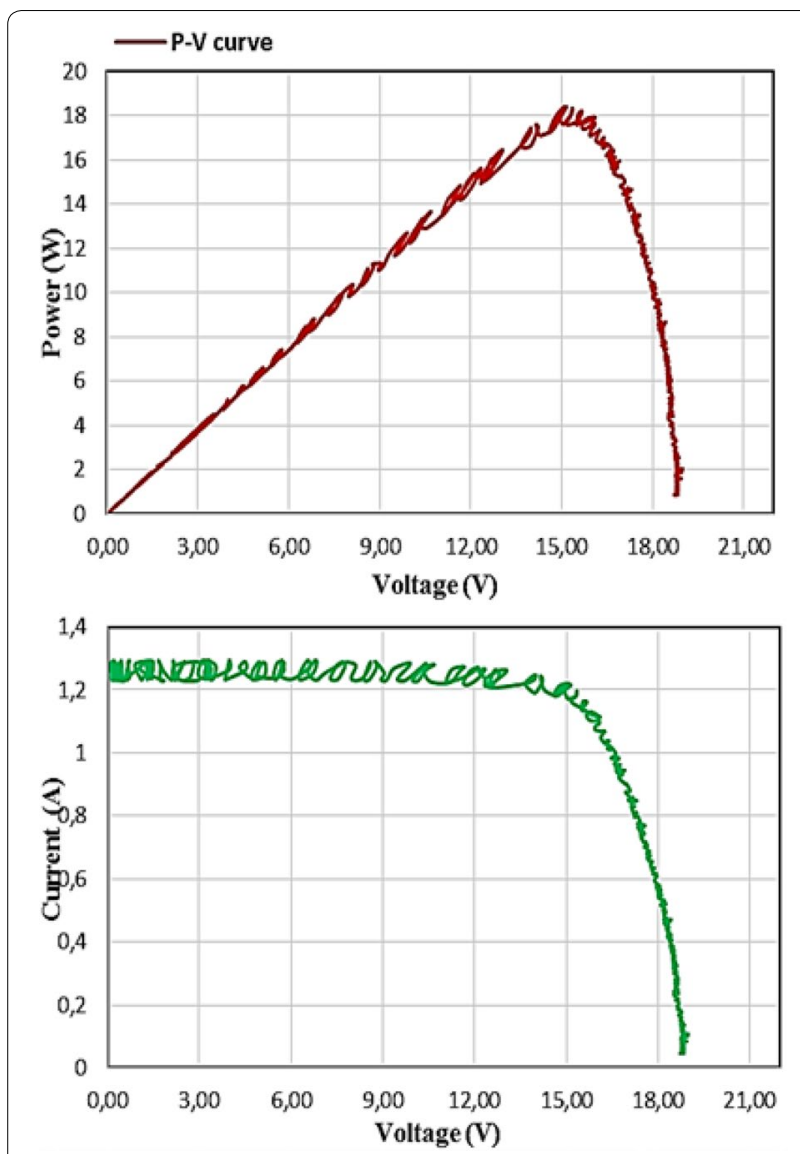

Fig. $19 I-V$ and $P-V$ characteristics for $P V$ panel by using with a sample time of $100 \mathrm{~ms}$ (at $T=71{ }^{\circ} \mathrm{C}$ and $\mathrm{G}=1130 \mathrm{~W} / \mathrm{m}^{2}$ )

as the present system is used such as a virtual instrument to acquire the PV panel characteristics under the real operation conditions, it can also be used on field periodical monitoring activities for PV systems.

The objective of this work was to present a novel virtual instrument for PV panel output characteristics which is simple and low cost. Table 8 presents a comparison between the proposed virtual instrumentation system price and that of different traditional instruments. The choice of an instrument is characterized by its price as well as by its technical characteristics, namely measuring accuracy, measurement margin, operating conditions and the possibility of recording the data. The proposed virtual instrument costs approximately $8.79 \$$. This instrument is made up of Arduino UNO board, a voltage sensor (F031-06) and current sensor (INA169). In addition, the software part consists of the Arduino embedded code and the PLX-DAQ data acquisition Excel Macro. Thus, if we want to improve our research, we can also add to our system other low-cost sensors such as the temperature (DS18B20) and irradiation (TSL230BRD-TR) sensors for monitoring the temperature and solar irradiation. On the other hand, traditional or classical instruments, such as multimeters and oscillators, are known for their high price. However, some exceptions of oscilloscopes have elements for recording data by USB as the PKT1265 intelligent oscilloscope $(438.12 \$)$, or in real time as the PCSU1000 developed oscilloscope (397.08\$), but these instruments are also more expensive. For multimeters, even assuming the use of the FLUKE 725 digital multimeter (2.90600 \$), known for its high measurement accuracy, it is very difficult and improbable to perform a correct reading from multimeter screen by a human in a situation of sudden changes in current or voltage even if an optimum human concentration is assumed. Consequently, small samples can be captured; then, the characteristics which traced manually do not reflect the real characteristics of the PV system. While a virtual robotic instrument, that is programmed with a predefined utility, instantly records each variation of measurement in the extreme and fastest cases that can be encountered. The proposed virtual instrumentation system in this paper enables users to monitor and trace the characteristics of a PV panel in a simpler, cheaper and faster manner. Our system is very useful for solar panels that have an output voltage margin between 0 and $25 \mathrm{~V}$, a current margin between 0 and $5 \mathrm{~A}$. For the large panels which generate a voltage and a current superior to those mentioned above, the Arduino code presented in this work remains the same with small modifications on a few lines of the program in which the microcontroller calculates the current and voltage that are acquired by the new voltage and current sensors. 
a Current monitoring
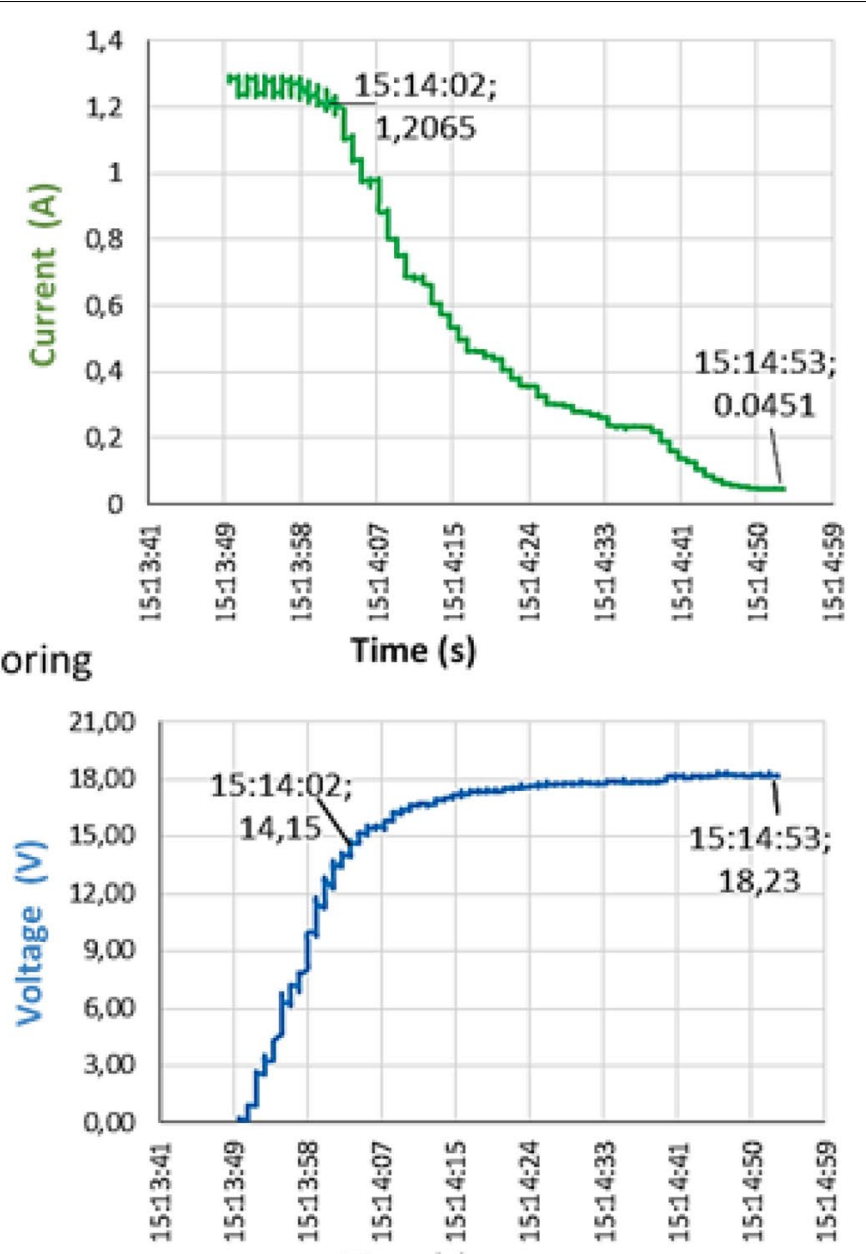

b Voltage monitoring

Time (s)

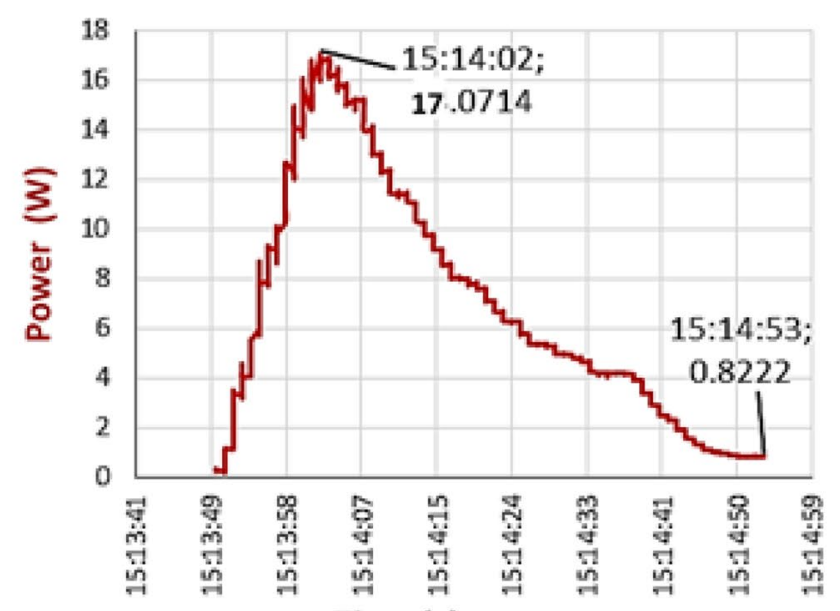

C Output power monitoring

Time (s)

Fig. 20 Monitoring of PV panel output characteristics: a current monitoring curve, b voltage monitoring curve, c output power monitoring curve (at $T=75^{\circ} \mathrm{C}$ and $\mathrm{G}=1100 \mathrm{~W} / \mathrm{m}^{2}$ ) 
Table 8 Price of the proposed virtual instrumentation system in comparison with that of traditional instruments

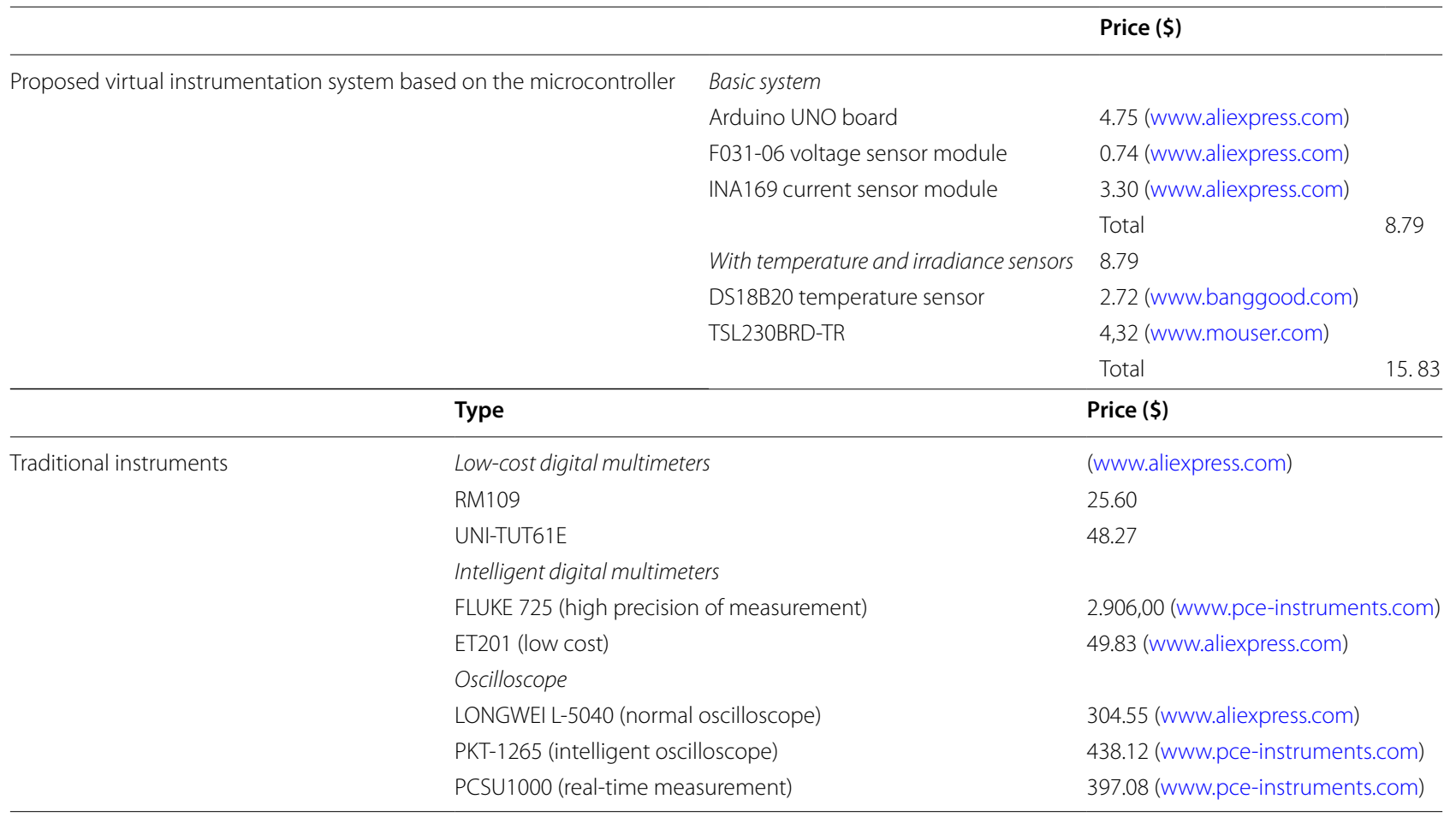

\section{Conclusions}

This paper describes a low-cost virtual instrumentation of PV panel characteristics based on Arduino and Excel. The proposed instrumentation system is able to make acquiring, monitoring and storing the data of the PV system in real time. Moreover, this instrument is validated in this work by comparing its experimental data with those obtained by a PSIM model of PV panel which has been verified by various researchers in their studies. The comparison results show that the PV characteristics acquired by our virtual instrument are in accordance with those obtained under PSIM with high accuracy. Also, a comparison between the proposed virtual instrumentation and traditional instrumentation using multimeters is made, and it has been found that our solution presents several benefits compared to the traditional solution such as the data can be presented in graphical form in real time. Thus, it can replace the human intervention to avoid possible errors related to data readings from multimeter as it is cheaper and saves a great deal of time. Therefore, the proposed system can facilitate the assimilation and recording of data as well as the creation and customization of reports that can be analyzed to improve the performance of PV systems.

\section{List of symbols}

a: diode's ideality factor; I: panel output current; /s: diode saturation current; / ph : panel photocurrent; $K$ : Boltzmann constant; $N_{s}$ : number of cells connected in series; q: electron charge; $R_{s}$ : series resistance; $R_{\text {sh }}$ : shunt resistance; $T$ : junction temperature; $V$ : panel output voltage; $V_{d}$ : output of voltage divider circuit.

\section{Abbreviations}

PV: photovoltaic; UART: universal asynchronous receiver transmitter; DC: direct current; STC: standard test condition; ADC: analog digital converter; USB: universal serial bus.

\section{Authors' contributions}

AELH and SM proposed the idea and the structure of the paper. AELH designed the overall hardware and software for the real-time virtual instrumentation system and implemented it. SM and AELG modeled the PV panel under PSIM. AELH and AC performed the experimental tests. AELH and SM wrote the paper. AELG, AC, and AD contributed to reviewing the paper. All authors of this research paper have directly participated in the planning, execution, or analysis of this study. All authors read and approved the final manuscript.

\section{Competing interests}

The authors declare that they have no competing interests.

\section{Ethics approval and consent to participate} Not applicable.

Funding

The authors declare that they have no funding for the research.

\section{Publisher's Note}

Springer Nature remains neutral with regard to jurisdictional claims in published maps and institutional affiliations.

Received: 2 September 2017 Accepted: 5 March 2018

Published online: 12 March 2018 


\section{References}

Arduino-Software. (2018). www.arduino.cc/en/Main/Software. Accessed 05 Jan 2018

Banu, E. I. V., \& Istrate, M. (2012). Modeling and simulation of photovoltaic arrays. In World Energy Systems Conference (Vol. 14, no. 3, pp. 1-6).

Chouder, A., Silvestre, S., Sadaoui, N., \& Rahmani, L. (2012). Modeling and simulation of a grid connected PV system based on the evaluation of main PV module parameters. Simulation Modelling Practice and Theory, 20(1), 46-58.

Eltawil, M. A., \& Zhao, Z. (2010). Grid-connected photovoltaic power systems: Technical and potential problems - A review. Renewable and Sustainable Energy Reviews, 14(1), 112-129.

Fuentes, M., Vivar, M., Burgos, J., Aguilera, J., \& Vacas, J. (2014). Design of an accurate, low-cost autonomous data logger for PV system monitoring using Arduino ${ }^{\mathrm{TM}}$ that complies with IEC standards. Solar Energy Materials and Solar Cells, 130, 529-543.

Alonsogarcia, M., Ruiz, J., \& Ghenlo, F. (2006). Experimental study of mismatch and shading effects in the I-V characteristic of a photovoltaic module. Solar Energy Materials and Solar Cells, 90(3), 329-340.

Hemza, A., Abdeslam, H., Rachid, C., Pasquinelli, M., \& Barakel, D. (2015). Tracing current-voltage curve of solar panel based on LabVIEW Arduino Interfacing. Bilişim Teknolojileri Dergisi, 8(3), 117-123.

Hohm, D. P., \& Ropp, M. E. (2003). Comparative study of maximum power point tracking algorithms. Progress in Photovoltaics: Research and Applications, 11(1), 47-62.

INA169 Datasheet. (2017). http://www.ti.com/lit/ds/symlink/ina169. pdf?HQS=TI-null-null-alldatasheets-df-pf-SEP-wwe.pdf. Accessed $25 \mathrm{Nov}$ 2017.

Jean, J., Brown, P. R., Jaffe, R. L., Buonassisi, T., \& Bulović, V. (2015). Pathways for solar photovoltaics. Energy \& Environmental Science, 8(4), 1200-1219.

Koutroulis, E., \& Kalaitzakis, K. (2003). Development of an integrated dataacquisition system for renewable energy sources systems monitoring Renewable Energy, 28(1), 139-152.

Mahrane, A., Guenounou, A., Smara, Z., Chikh, M., \& Lakehal, M. (2010). Test bench for photovoltaic modules. In International Symposium on Environment Friendly Energies in Electrical Applications.

Motahhir, S., Chalh, A., El Ghzizal, A., Sebti, S., \& Derouich, A. (2017a). Modeling of photovoltaic panel by using proteus. Journal of Engineering Science and Technology Review, 10(2), 8-13.

Motahhir, S., El Ghzizal, A., Sebti, S., \& Derouich, A. (2015). Proposal and Implementation of a novel perturb and observe algorithm using embedded software. In IEEE international renewable and sustainable energy conference (pp. 1-5).
Motahhir, S., EL Ghzizal, A., Sebti, S., \& Derouich, A. (2015). Modélisation et commande d'un panneau photovoltaïque dans l'environnement PSIM. In Congrès International de Génie Industriel et Management des Systèmes, CIGIMS.

Motahhir, S., El Ghzizal, A., Sebti, S., \& Derouich, A. (2016). Shading effect to energy withdrawn from the photovoltaic panel and implementation of DMPPT using C language. International Review of Automatic Control, 9(2), $88-94$.

Motahhir, S., El Ghzizal, A., Sebti, S., Derouich, A. (2017). Modeling of photovoltaic system with modified incremental conductance algorithm for fast changes of irradiance. International Journal of Photoenergy (in press).

Ozdemir, S., Altin, N., \& Sefa, I. (2014). Single stage three level grid interactive MPPT inverter for PV systems. Energy Conversion and Management, 80 $561-572$

PLX-DAQ. (2017). https://www.parallax.com/downloads/plx-daq. Accessed 15 Dec 2017.

Santos, D., \& Setiaji, F. D. (2013). Data Logger Parameter Panel Surya. Thèse de doctorat, Program Studi Teknik Elektro FTEK-UKSW.

Silvestre, S. (2003). Review of system design and sizing tools. Practical handbook of photovoltaics: fundamentals and applications. Oxford: Elseviers.

Singh, G. (2013). Solar power generation by PV (photovoltaic) technology: A review. Energy, 53, 1-13.

TDC-M20-36 solar panel. (2018). https://tdcsolar.en.alibaba.com/ product/60018196685-220763581/20w_mono_small_solar_panel_from_ chinese_factory.html?spm=a2700.8304367.rect38f22d.16.471851980cA XoD. Accessed 10 Jan 2018.

Ulieru, V. D., Cepisca, C., \& Ivanovici, T. R. (2010). Measurement and analysis in $\mathrm{PV}$ systems. In Proceedings of the international conference on circuits, ICC (pp. 22-24).

Velleman Instruments. (2017). https://www.velleman.eu/products/ view/?id=362986. Accessed 23 Dec 2017

Villalva, M., Gazoli, J., \& Filho, E. (2009). Comprehensive approach to modeling and simulation of photovoltaic arrays. IEEE Transactions on Power Electronics, 24(5), 1198-1208.

Voltage Sensor Module. (2018). http://www.emartee.com/product/42082/ Voltage\%20Sensor\%20. Accessed 01 Jan 2018.

\section{Submit your manuscript to a SpringerOpen ${ }^{\circ}$ journal and benefit from:}

- Convenient online submission

- Rigorous peer review

- Open access: articles freely available online

- High visibility within the field

Retaining the copyright to your article

Submit your next manuscript at $\boldsymbol{\nabla}$ springeropen.com 